\title{
Public Policy Committee guidance on medical aspects of fitness to drive
}

The Driver and Vehicle Licensing Authority (DVLA) re-issued in 1995 new guidelines on "Medical Aspects of Fitness to Drtve - A Guide for Medical Practitioners" (Medical Commission on Accident Prevention). Doctors are advised that they should inform patients if they suffer from a condition which makes them unfit to drive and it is then the patient's duty to inform the DVLA. Notification to the DVLA of major psychiatric illness, defined as requiring admission or major intervention, will result in suspension of the licence for a period of time in the following circumstances:

1. Where the mental state is seriously unstable or there is significant impairment of concentration or judgement.

2. Where essential medication is likely to impair safe driving.

3. Where the patient is not compliant to essential medicine.

4. In any case where a mental disorder significant to safe driving is expected to last for more than 3 months.

Patients taking psychoactive medications should particularly be warned never to take alcohol before driving.

The Public Policy Committee recommends that:

(i) it is the responsibility of the doctor to advise the patient when it is unsafe to drive and to recommend that he/she should inform the DVLA:

(ii) information concerning driving should be a standard part of the advice given to all psychiatric patients, despite concerns about the patient/doctor relationship;

(iii) when advising a patient, this should be recorded in their notes; (iv) that the doctor should consider writing to the patient to avoid any claims of negligence from the patient if the condition is such that it will significantly affect the patient's driving:

(v) if the patient refuses or is unable to inform the DVLA and the doctor feels that there is a significant risk to the patient or others, advice should be sought from a medical defence society. The General Medical Council's guidelines (GMC, 1995a,b) on acting without a patient's consent should be followed before confidentiality is broken.

(vi) members should at all times be aware of the current DVLA guidelines.

Membership should be aware that a new EC Directive on Driver Licensing came into force in August 1996 which brings in important changes to the health standards for new drivers.

\section{Further reading}

HuMpHREYs, S. A. \& Roy. L. (1995) Drtving and psychlatric illness. Psychiatric Bulletin, 19, 747-749.

\section{References}

GENERAL MEdical CouncIl (1995a) Confidentiality Disclosure of confidential information with the patient's consent. In Duties of a Doctor. Guddance From the General Medical Councl. pp. 4-5. London: GMC.

- (1995b) Appendix I. In Dutles of a Doctor. Gutdance From the General Medical Councll, pp. 11-12. London: GMC.

Medical Commission on Accident Prevention (1995) Medical Aspects of Futness to Drive. A Guide For Medical Practitioners, pp. 109-117. 